\title{
MEXTEX S.A. ESTRATEGIAS ADMINISTRATIVAS: PEQUEÑAS EMPRESAS*
}

\author{
Sérvulo Anzola Rojas
}

$\mathbf{P}$

reocupado por la administración de su empresa, el Licenciado Eduardo González Pérez, gerente general de MEXTEX S.A., invito a dos expertos a llevar a cabo una inspección in situ. Previa cita, los señores Raúl Peña y Rubén Sánchez se presentaron una mañana ante el señor Pedro Escobar, gerente administrativo de la empresa.

-Es un placer atenderlos, señores. EI Lic. González Pérez me ha platicado de ustedes y quisiera ofrecerles la más cordial bienvenida. Si lo desean, ahora mismo podemos iniciar el recorrido por la planta industrial -Pedro Escobar les mostró el camino hacia el área de etiquetado.

-Muchísimas gracias por su ayuda -dijo Raúl Peña mientras caminaban-, quisiéramos hacerle unas cuantas preguntas. ¿Con cuánto personal cuenta la empresa?

- Segundo premio en el área de Administracióa. Concurso de Casos de Cl.ADEA 19901991.
-A nivel gerencial estamos el gerente general, que es además gerente de producción. un servidor y un ingeniero encargado del departamento de producción. En cuanto al personal administrativo, tenemos una secretaria y un cobrador-vendedor. En el nivel operativo contamos con doce trabajadores, dos de ellos supervisores. Yo me ocupo solo de todas las funciones administrativas $y$ de ventas $y$ el tiempo no me alcanza. Por eso los voy a acompafiar solamente un momento.

-Parece que no hay mucho movimien. to-Rubén Sánchez se extraño- ¿No tienen mucho trabajo?

-Pues mire usted -Pedro Escobar se volvió-, la crisis economica de hoy en día ha ocasionado que la industria de la construcción y el gobierno nos reduzcan sus pedidos.

- ¿Y cuánto trabajo tienen los empleados? -preguntó Raúl Peña. 
-Tienen mucho trabajo, pero solamente laboran un poco menos de la mitad del tiempo.

-¿Podría señalar un porcentaje exacto? -intervino el otro experto.

-Dejeme ver ... tres horas y media. Y el resto del tiempo, cuatro horas y media, lo dedican a limpiar, revisar o a darle mantenimiento a las máquinas. Además les queda un poco de tiempo libre.

$-i$ Conforme a qué trabajan los obreros? -indagó Raúl Peña.

-Conforme a las órdenes directas que les dan los supervisores y los gerentes. A todo esto, algunos son un tanto lerdos y a cada rato se les tiene que repetir lo que deben hacer.

- ¿Cómo reclutan al personal? -Rubén Sánchez miraba con atención al grupo de obreros afanados con una mexcla.

-La empresa pone anuncios en el periódico y los gerentes entrevistamos a quienes se presentan. Luego los supervisores se encargan de enseñarles el trabajo a los contratados -Pedro Escobar miró su reloj-. Discúlpenme, pero ya voy a tener que dejarlos, dentro de un momento tengo una cita con un cliente que al parecer nos hará un pedido muy grande.

-Por nosotros no se incomode, $¿$ le sucede esto muy a menudo? -Raúl Peña lo miró con algo de preocupación.

-Sí, a cada rato. $\mathrm{Y}$ el andar de vendedor me tiene en jaque, me desentiendo de las otras actividades que debo desempeñar en la empresa. $Y$ ahora no nos podemos dar el lujo de perder citas o contactos.
-Sólo una última pregunta -lo retuvo Rubén Sánchez- ¿cómo elige a sus clientes?

- La verdad de las cosas es que yo no los escojo, se presentan por sí mismos. Pero eso sí, quisiera que me ayudaran a encontrar la forma de dar con los mejores clientes. Este es un problema que nos está afectando mucho actualmente.

-Estamos para servirle y muchísimas gracias por todas sus atenciones -Rubén Sánchez y Raúl Peña estrecharon su mano.

-Ya saben que estoy a su disposición para lo que se les ofrezca-Pedro Escobar se retiró presuroso.

-Oye, Peña, yo nunca había oído mencionar a MEXTEX. ¿No crees que serfa conveniente regresar para hacerle algunas sugerencias al gerente administrativo?

-Claro, de eso se trata. Por lo que hemos oído, yo pienso que la empresa tiene algunos problemas que debe resolver. Sería fácil detectarlos, pero tendríamos que analizar a fondo su situación financiera (ver anexo).

\section{La empresa}

La Empresa MEXTEX S.A. fue fundada el 25 de mayo de 1979 con un capital social de \$ 5.000.000 (cinco millones de pesos). La distribución de este capital puede apreciarse en el cuadro siguiente.

Los objetivos de la sociedad eran los siguientes: fabricación de pinturas, esmaltes, barnices, recubrimientos industriales; compra-venta de productos químicos; representaciones; comisiones de artículos 
comerciales e industriales; prestación de servicios de asesoría técnica relacionada con el ramo de la industria química; celebración de actas y contratos de toda clase; compra-venta o renta de todos los bienes muebles $\mathrm{e}$ inmuebles necesarios para el buen funcionamiento de la sociedad. con los medios para brindarles un adecuado mantenimiento. La mayoría de ellas necesitan ser pintadas, pero el alto costo de las pinturas y los pocos canales de distribucion de estos productos no lo permiten. Los directivos de MEXTEX S.A. consideran que este sector de población constituyc un mercado amplio al que se puede llegar utilizando la experiencia de la empresa en la fabricación de pinturas comerciales. Además cuentacon la maquinaria para el proceso, el equipo de laboratorio $y$ la infraestructura necesaria para obtener un producto de bajo precio.
$\$ 1.500 .000$

500.000

500.000

2.000 .000

500.000

s 5.000 .000
En 1980 la sociedad decidió aumentar el capital hasta \$ 15.000.000 para incrementar las operaciones $\mathrm{y}$ fortalecer la economía de la empresa.

Las instalaciones de MEXTEX S.A. están en perfecto estado y son lo suficientemente amplias como para que en ellas se realicen las labores de venta, administración y producción. Están ubicadas en una avenida principal de la ciudad de Monterre y ocupan una superficie de 2.600 metros cuadrados. La fachada alcanza 25 metros. La zona es considerada industrial, la $\mathrm{em}$ presa está rodeada de bodegas, distribuidores, fabricantes de partes automotrices, transportistas, empresas del ramo metal mecánico, etc.

\section{Organización y mercado}

Gran parte de las casas-habitación en México son de interés social y sus propietarios -clase media, media-baja, baja-alta y baja-baja-, por lo general, no cuentan

(1)

\begin{tabular}{|c|c|c|}
\hline Accionistas & Acciones & Valor \\
\hline Lic, Eduardo González Pérez & 150 & $\$ 1.500 .000$ \\
\hline Sra. Maria Pérez de Genzillez & so & 500.000 \\
\hline Sr. Augusto Gonzallez Ptrez & 50 & 500.000 \\
\hline C.P. Manuel Ptrez Gonźllez & 200 & 2.000 .000 \\
\hline Sra. Sofia González Pérez & so & 500.000 \\
\hline Total & 500 & 55.000 .000 \\
\hline
\end{tabular}

Los directivos de la empresa consideran que la buena calidad del producto y sus amplios canales de distribución podrían cubrir el mercado habitacional de interés social compuesto por:

- casas-habitación de interés social

- edificios de dependencias del gobierno

- condominios habitacionales

- condominios multifamiliares y

- casas-habitación en colonias populares

La empresa basa su seguridad para la penetración de este mercado en las siguientes razones:

a) Bajo precio de los productos.- Para elaborar pinturas vinílicas a bajo precio se requiere una formulación adecuada, en la que las distintas sustancias -resina, pigmentos, aditivos, espesantes, humectantes, fungicidas, etc. - se combinen en proporciones tales que permitan un bajo costo de fahricación 
b) Calidad.- Las materias primas mencionadas en el punto anterior son de las mejores marcas, de forma que con el correcto proceso de fabricación, la investigación constante en los laboratorios y el proceso de pruebas de control de calidad, se espera obtener productos de buena calidad comercial.

c) Canales de distribución.- La empresa ha podido comprobar que los canales de distribución de pinturas en general son muy inferiores en número a las necesidades de la gran cantidad de clientes, aunque pretenden estar en lugares aparentemente estratégicos. Debido a esto se considera que lo más adecuado son las grandes tiendas de autoservicios, las ferreterías, las tlapalerias y todos aquellos centros comerciales en los cuales sc distribuyen la mayoría de los productos.

División administrativa, departamentos y áreas de la empresa

El máximo órgano de la empresa es el Consejo de Administración, integrado por los accionistas, el que nombra al gerente general y establece sus atribuciones y responsabilidades.

La descripción de los puestos y sus responsabilidades son fijadas por la gerencia general. Cada persona que labora en la empresa recibe las especificaciones correspondientes al puesto que desempeña.

La selección de las personas que ocupan los cargos ejecutivos no es la adecuada, ya que se hace a partir de recomendaciones (cartas) de gente de confianza de otras empresas. Se puede decir que el entrenamiento y la capacitación de quienes ingresan a la compañía es hecha en forma empírica. La descripción del puesto es entregada por escrito pero luego no se hace un seguimiento formal. Los ejecutivos trabajan "sobre la marcha" y con base en conocimientos empíricos.

La empresa otorga incentivos económicos: sueldos, salarios, comisiones, gratificaciones $y$ aguinaldos, $y$ hasta la fecha no $\mathrm{se}$ han producido conflictos que pudieran resultar perjudiciales para los subordinados o para la empresa o que pudieran ocasionar problemas legales.

La gerencia de la empresa tiene conocimiento de las expectativas de los trabajadores en cuanto a los incentivos monetarios y piensa que ésta es la única forma de mantener a las personas motivadas para llevaracabolas tareas queles son asignadas.

Las relaciones entre los gerentes y los subordinados son bastante estrechas. Se acostumbra realizar juntas semanales con todos los miembros de la empresa con el propósito de escuchar inquietudes, recibir sugerencias y resolver problemas internos.

La empresa cucnta con un modesto equipo de seguridad dentro del área de trabajo -incluidas las oficinas-, aunque el gerente general dice que MEXTEX, en comparación con la industria de pinturas, ostenta un récord menor en cuanto a ocurrencia de accidentes y, sobre todo, incendios.

\section{Recursos materiales}

La manera en que la organización determina la necesidad de recursos para la producción es por medio de la formulación química secreta, realizada con base en fórmulas para la obtención de colores v para 
la fabricación de esmaltes y pinturas vinílicas. Sólo el gerente puede alterar estas formulaciones a través del departamento de producción.

La empresa cuenta con sistemas sofisticados de cuidado industrial: tableros eléctricos y motores antiexplosion que miden y minimizan, respectivamente, el riesgo de accidentes. El mantenimiento que se le da al equipo es casi totalmente correctivo.

\section{Producción}

Es en este departamento $y$ en la gerencia general donde se realiza toda la planeación de las necesidades de equipo. No hay una disposición adecuada del espacio de la planta, pero sí una completa funcionalidad para las operaciones asociadas con la producción. Los aspectos de seguridad e higiene son considerados de suma importancia.

Se trata de llegar a una colocación óptima y funcional de equipo -existen manuales técnicos interpretados por el ingeniero jefe-, ya que de otra manera las operaciones de carga y descarga del producto terminado serian incómodas para los camiones de carga y para los peones cargadores.

No existen desperdicios de materiales dentro de la planta, a excepeión del papel con que se envuelven los pigmentos. A fin de mes, el Departamento de Producción vende este papel y con lo recaudado acostumbra organizar una pequeña fiesta (carne asada) para su personal.

El sistema de trabajo del departamento consiste en cntregar $y$ hacer cumplir ordenes de trabajo o instrucciones concernientes a la transformación de la materia prima, ya que el ingeniero encargado de la planeación y el gerente general consideran que es la única forma de trabajar.

La compañía acostumbra realizar, cada seis meses, pruebas comparativas con productos similares (esmaltes, barnices y vinflicas) de las empresas de la competencia en cuanto a secado, porosidad, color y recubrimiento. Todas las muestras son guardadas seis meses para poder hacer pruebas y comprobaciones químicas posteriores.

La empresa es miembro de ANAFAPy T (Asociación Nacional de Fabricantes de Pinturas y Tintes) a nivel local, una agrupación del gremio de fabricantes de pinturas que brinda a sus afiliados constante información sobre nuevos productos aparecidos en el mercado, así como también sobre nuevas fábricas productoras de pintura, barnices y esmaltes.

La gerencia general está consciente de que a medida que transcurra el tiempo se irán haciendo necesarios algunos ajustes en el proceso productivo.

El proceso de producción: esmaltes, barnices y primarios (ver Figura I)

Se sigue el procedimiento siguiente:

a) Materias primas.- Consiste en la formación de pasta con proporciones variables de resinas, pigmentos, aditivos y solventes.

b) Humectación.- Agitación de la pasta en el equipo Cowles Dissolver hasta alcanzar una homogenización completa. 
c) Molienda.- La operación se lleva a cabo en el molino de arena San Mill.

d) Reducción.- En esta parte del proceso se agregan más resinas, aditivos, secantes, antinatas y solventes (control de viscosidad), y se le da a la pasta el "entonado final" con una nueva agitación en el equipo Cowless Dissolver.

c) Terminado.- En este momento se llevan a cabo las pruebas de control de calidad.

f) Envasado y etiquetado.- El producto final es envasado en latas de $1,2,3,4$ y 18 litros.

g) Almacén de producto terminado.-EI producto final envasado está listo para su venta.

El proceso de producción: pinturas vinilicas

a) Materias Primas.- Consiste en la formación de pasta con proporciones variables de resina, pigmentos, aditivos espesantes y otras sustancias (humectantes, fungicidas, dispersantes, etc.).

b) Agitado.-Consisteen la agitación de la mezcla de materias primas en el equipo Cowles Dissolver hasta alcanzar una homogenización completa.

c) Reducción.- En esta parte del proceso se agregan más resinas, aditivos, secantes, y se le da a la pasta el "entonado final" con una nueva agitación en el equipo Cowless Dissolver.

d) Envasado y etiquetado.- El producto final es envasado en latas de 1, 4 y 18 litros. e) Almacén de producto terminado.-El producto final envasado está listo para su venta.

\section{Comercialización}

MEXTEXS.A. ha establecido un sistema de ventas a distribuidores en sus actuales zonas de trabajo en la ciudad de Monterrey, N.L. y áreas foráneas (Sinaloa, Coahuila, Tamaulipas, Chihuahua, Veracruz, etc.). Este consiste en:

\section{Ventas:}

Lista de precios

a) General (público)

b) Contratista ( 25 por ciento menos que la general)

c) Distribuidor (35 por ciento menos que la general)

d) Bonificación por consumo mínimo (contrato del distribuidor)

\section{Forma de pago:}

Distribuidores

a) Stock inicial (mínimo $\$ 100.000)$ al contado.

b) Compras posteriores, a 30 días con documento aceptado.

c) Para que el distribuidor obtenga el beneficio de la escala de bonificación por consumo deberá estar al corriente de sus pagos en el momento del cálculo trimestral de sus compras.

d) Se otorgará un descuento adicional de 4 por ciento por pronto pago (a 10 días de la fecha de factura).

Las bases anteriores, así como la exclusividad en el área que les corresponde, son válidas únicamente para los distribuidores clientes. Para los distribuidores foráncos $\mathrm{cl}$ stock inicial debe ser de $\$ 2.000 .000$, pero las otras condiciones son similares. 


\section{Condiciones de distribución:}

a) Para ser distribuidor de los productos MEXTEX, el cliente deberá estar establecido y tener penetración en el mereado de la zona en donde se localiza.

b) MEXTEX S.A. ofrece al distribuidor la exclusividad en siete cuadras a la redonda para la protección de sus ventas de mostrador, siempre y cuando éste cumpla con los requisitos de ventas, créditos, existencias, pagos, etc. Queda a criterio de la gerencia de ventas si se cambia o aumenta la cantidad de distribuidores en la zona.

c) Para las ventas directas o especiales se utilizan condiciones y precios fijados y controlados por la gerencia de ventas y la gerencia general.

d) Cuando el distribuidor solicita algún producto especial o de la línea indus. trial, lo obtiene de acuerdo con los descuentos y/o los precios fijados por MEXTEX S.A. y la gerencia correspondiente. Estas compras están sujetas a las mismas condiciones estipuladas en el contrato del distribuidor.

Para todos estos servicios MEXTEX S.A. cuenta con vendedores que asigna por zonas y cuyo trabajo consiste en asesorar al distribuidor $\mathrm{y}$ a sus clientes respecto de los nuevos productos, precios, información técnica y en cualquier otro servicio que le fucra solicitado. Así mismo, el vendedor ayuda al distribuidor a impulsar sus ventas canalizando por su conducto las peticiones o resultados de su labor de contratista, industrial, etc.

La división industrial cubre todo el territorio nacional. Las zonas son las siguicntes:
- Zona Norte Golfo: Nuevo León, Tamaulipas y Veracruz.

- Zona Norte Pacífico: Coahuila, Durango, Chihuahua, Sinaloa, Sonora y Baja California.

-Zona Centro: Distrito Federal, Hidalgo, Querétaro, Guanajuato, Jalisco, Michoacán, Colima, Guerrero y Pucbla.

Lapublicidad está enfocadaúnicamente a los productos nuevos y especiales y se realiza a través de radioemisoras, periódi$\cos$, tarjetas de presentación y avisos luminosos.

La promoción se limita solo a abridores (destapadores), cachuchas (gorras), camisetas y muestrarios que los representantes se encargan de distribuir.

La gran promoción de ventas de la división industrial está dirigida al gobierno y sólo en una pequeña proporción a contratistas privados $\mathrm{y}$ a la industria. Las condiciones de venta que emplea siempre son más benévolas, en plazos y descuen. tos, para los contratos con el gobierno.

\section{Bonificación por consumo}

La empresa concede al distribuidor bonificaciones por consumo que liquida en forma trimestral dentro de los 20 días siguientes al cierre de cada trimestre terminado respectivamente en abril, julio, octubre $\mathrm{y}$ enero de cada año.

El distribuidor tiene derecho a dicha bonificación si está al corriente de sus pagos. Ver cuadro siguiente.

\section{Reporte de visita}

Los vendedores presentan diariamente informes escritos, los que constituyen la ú- 
Escala de Bonificación por Consumo Compras Trimestrales

des 0

de $\$ 10.000 .001$

de $\$ 18.000 .001$

de $\$ 27.000 .001$

de $\$ 37.500 .001$
\$ 10.000 .000

$\$ 18.000 .000$

$\$ 27.000 .000$

$\$ 37.500 .000$

en adelante
$1,0 \%$ Bonificación

3,5\% Bonificacion

$7,0 \%$ Bonificacióa

$10,5 \%$ Bonificación

$15,0 \%$ Bonificación de este canal. Las políticas de comercialización incluyen rebajas por volumen de compras y descuentos por pronto pago. nica fuente de información del gerente. Este ha impuesto el siguiente lema a los vendedores: "No lo diga, escribalo".

Los vendedores emplean el siguiente procedimiento para localizar clientes:

a) Estudiar la zona de ventas que se les ha asignado.

b) Localizar dónde se realizan las compras de pintura y quiénes las hacen. Consultar con la industria, contratistas, arquitectos, etc. que se encuentren en su zona.

c) Utilizar los formularios para estudio de mercado y procurar contestar todas las preguntas con resultados reales.

d) Considerar la forma de conquistar a su prospecto, qué problemas tiene, qué ayuda necesita, etc.

e) Escoger los mejores prospectos, hacerles llenar una solicitud de crédito y asegurarse que ésta sea aceptada.

En la actualidad, MEXTEX S.A. sólo participa en la línea comercial (clásica) del ramo de pinturas -una participación de entre 1 y 2 por ciento aproximadamente-, pero no en el ramo de pinturas de uso industrial ni en el de pintura automotriz.

La empresa tiende a utilizar distribuidores porque toda la venta se hace a través ductos se establecen sumando un margen de utilidad al costo y en lo posible se mantienen por debajo de los ofrecidos por la competencia.

El otorgamiento de crédito a clientes es básico para la compañía, pues la mayor parte de las ventas se realizan a crédito sobre la base de 30 días. En la actualidad, dada la situación del país, los plazos de cobro de la cartera se han tenido que ampliar. No obstante, no se ha establecido recargos por intereses. La cartera se ha manejado en forma normal hasta fines de 1990, desde entonces las cuentas por cobrar se han incrementado, pero no en forma alarmante.

\section{Objetivos y planes de Relaciones Indus- triales}

Trimestralmente el gerente convoca a junta de accionistas para discutir y llegar a un acuerdo respecto de la dirección general de los planes objetivos de los departamentos.

Los jefes de departamento son responsables de las decisiones que se tomen en sus respectivas áreas.

Cuando ocurre algún problema que involucra a determinada persona, corresponde resolverlo a su jefe inmediato. Sólo si éste no puede hacerlo se traslada el caso al gerente general. 
A los trabajadores se les permite hacer sugerencias para mejorar la producción o su calidad.

La única seguridad con que cuenta la empresa es la presencia de dos perros polícias raza doberman. Pero también se beneficia de la vigilancia externa del personal de seguridad de las compañías vecinas.

La información es centralizada en la gerencia y luego se distribuye a los distintos departamentos.

\section{Control de personal}

Cada jefe de departamento tiene programados planes de desarrollo para su personal, uno a un año y otro a cinco años. El segundo está sujeto a los resultados del primero; y el primero, a los ajustes económicos de la empresa.

Los flujos de trabajo se programan conforme a los pedidos y se da preferencia a los pagados en efectivo.

Las reglas y normas son conocidas por todo el personal y se respetan al pie de la letra.

Las líneas de comunicación al interior de la empresa son completamente libres, pero se dirigen al gerente general cuando se trata de asuntos formales.

\section{Area contable}

La empresa lleva un catálogo de cuentas de manera muy informal, carece de instructivo de cuentas y de personal capacitado para su manejo.

Las formas que utiliza la empresa para el registro de sus operaciones corresponden en su mayor parte -70 por ciento- a métodos establecidos en el mercado (Printaform) y que no se adecúan a sus necesidades. La empresa cuenta con un despacho contable que maneja los registros de operaciones, paga los impuestos y efectúa el reparto de utilidades.

\section{Relaciones Públicas}

La empresa mantiene trato directo con los distribuidores mayoristas $y$ relaciones muy estrechas con sus competidores, al grado que se prestan materia prima sin costo adicional. Con los bancos existe una relación muy fluida.

El vínculo con sus accionistas es casi cotidiano, porque se les reporta contratos importantes o préstamos a la empresa. Además, anualmente se convoca a junta general de accionistas. 


\section{NOTA PEDAGOGICA}

El presente caso ha sido preparado para ser utilizado en cursos de administración en general, cursos de integración administraliva y cursos de administración de empresas estratégicas.

Por ejemplo en:

- Procesos administrativos

- Toma de decisiones administrativas

- Administración de pequeñas empresas estratégicas

- Estructuras y procesos organizacionales

- Estrategias administrativas

- Plancación y control administrativos

Los lectores del caso deberán centrar su atención en la problemática que enfrentan las cmpresas en sus niveles administrativos y directivos, esto es, en el papel de los licenciados en Administración de Empresas, los contadores públicos, los profesionales con maestría en Administración.

El caso también podría ser usado por los estudiosos de la problemática estratégica de la pequeña empresa. Los temas centrales que se presentan -administración, contabilidad y finanzas, mercadeo y producción- giran en torno a los cursos comúnmente dictados en las escuelas de administración, incluyendo a las universidades $\mathrm{e}$ instituciones con programas de pos-grado en administración.

El caso pretende lograr en el alumno, desde el punto de vista del proceso enseñanza-aprendizaje, la selección, comprensión, análisis, cvaluación y síntesis de una problemática administrativa real por me- dio de la aplicación de las herramientas y técnicas administrativas aprendidas durante sus estudios. El debe analizar y evaluar la situación y plantear la solución más factible al problema principal.

El caso, además, permite al alumno aplicar to aprendido en un contexto organizacional definido por los ambientes interno y externo, y específico a la problemática gerencial, directiva y/o administrativa de manera integral.

\section{Preguntas para la discusión}

¿Cuál considera usted sea el problema principal interno de la empresa?

¿Cuál considera usted sea el problema principal externo de la empresa?

¿Qué incongruencia básica se presenta entre la información que se proporciona de la empresa y la que da el gerente administrativo?

¿Qué problema principal percibe usted a partir del diálogo que sostiene el gerente administrativo con los señores Sánchez y Peña?

¿Cuál es el problema principal de la empresa con relación a los distribuidoreso clientes y cómo afecta esto a la empresa? Justifique su respuesta.

¿En cuanto al proceso de producción, ¿qué se puede deducir del proceso técnico de la elaboración de pinturas y cómo esto afecta a los inventarios? 
¿Qué planeamiento de tipo estratégico se podría diseñar para englobar todos los puntos anteriores y analizar la situación de la empresa en cuanto a producción, finanzas, mercados y personal para resolver su problema principal?

Análisis general para ayudar a identificar y clarificar los puntos cruciales

Uno de los aspectos más relevantes de este caso es la incongruencia entre la información que se proporciona de la empresa y la realidad de la empresa.

Aparentemente el gerente es una persona que conoce muy bien la teoría, pero no la lleva a la práctica. Prueba de esto podría ser el sistema de ventas, pues aunque se menciona una serie de reportes y estrategias a través de los canales de distri. bución, no parece prestarse mucha atención a la venta de los distribuidores, además se depende especificamente de un cliente: el gobierno (Instituto Nacional de Fomento a la Vivienda), lo cual podría resultar funesto para el futuro de la empresa.

Por otro lado, del diálogo sostenido se desprendeque los trabajadores dedican a la producción sólo entre el 50 y el 60 por ciento de su tiempo.

Las pinturas generalmente requieren de muchas materias primas para su elaboración; en consecuencia, es muy importante pensar $\mathrm{cn}$ la posibilidad de un sistema de control más automatizado.

A continuación, para facilitar el análisis completo de la empresa y la toma de decisiones, se presenta un planteamiento estratégico fundamentado en los estudios cuantitativos y cualitativos de cada punto (ver Figura 2).

Como comentario concluyente, se podría decir que el caso da al estudiante la oportunidad de aplicar herramientas y técnicas administrativas de carácter estratégico con énfasis en la planeación y el control de una empresa pequeña o mediana que adolece de coordinación y de integración al interior de cada área y de la empresa como un todo.

Además, como ya se ha mencionado, el caso ayuda a integrar los conocimientos administrativos del estudiante dentro del proceso enseñanza-aprendizaje y de acuerdo a las disciplinas sugeridas. 


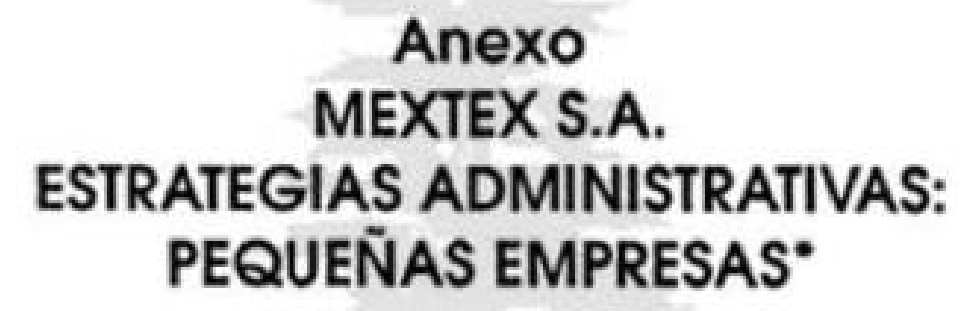




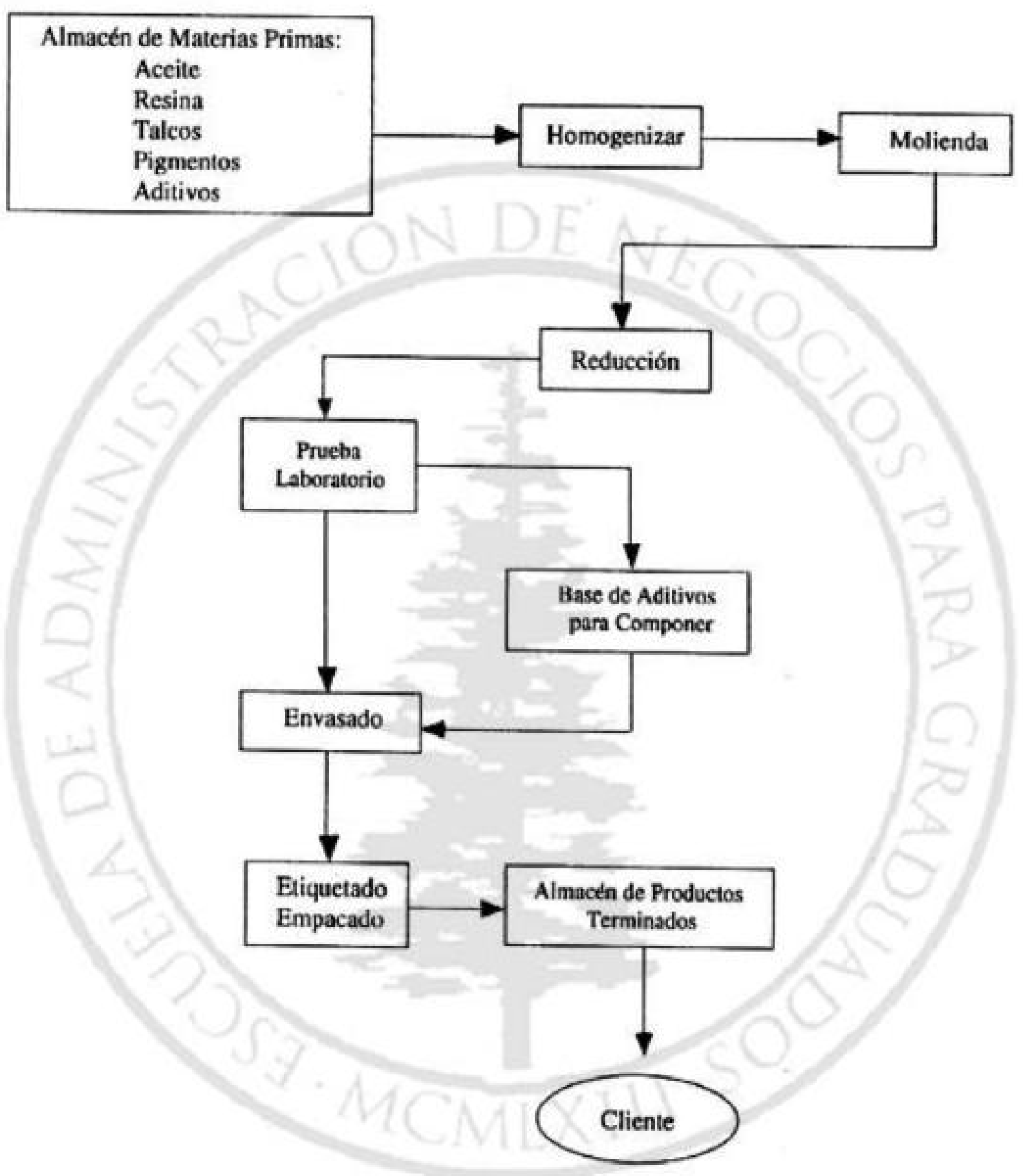

PROCESO DE FABRICACION 


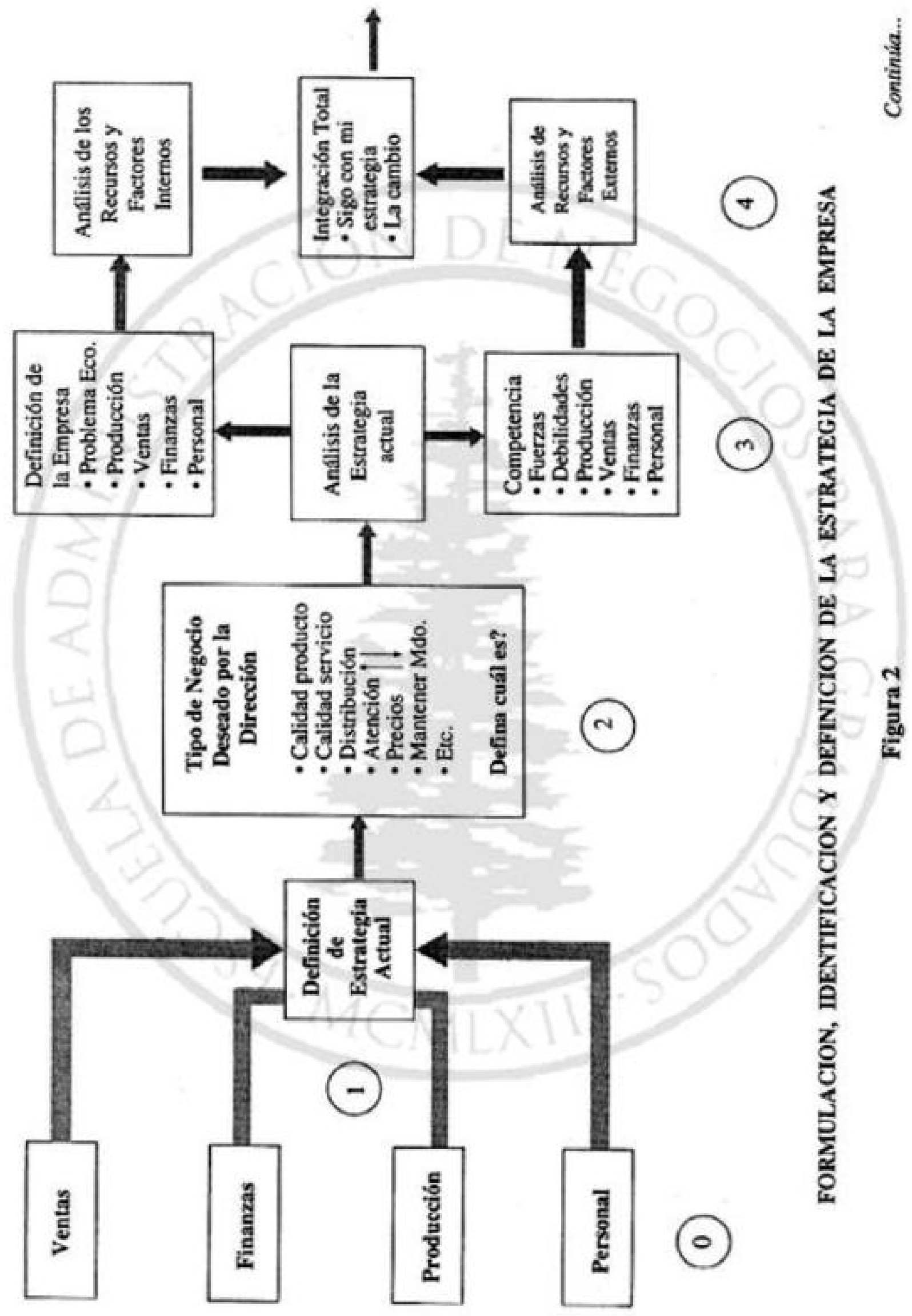




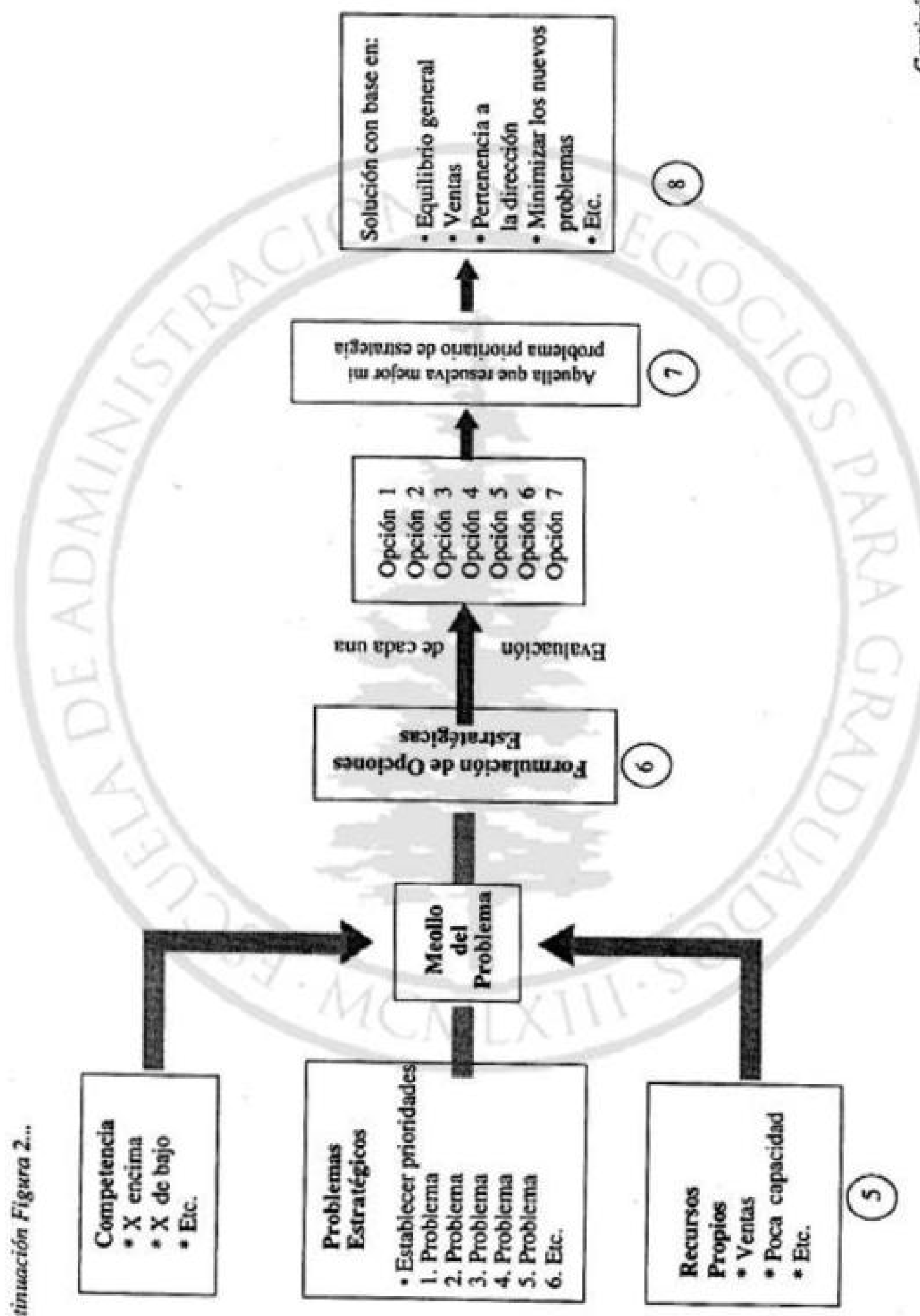




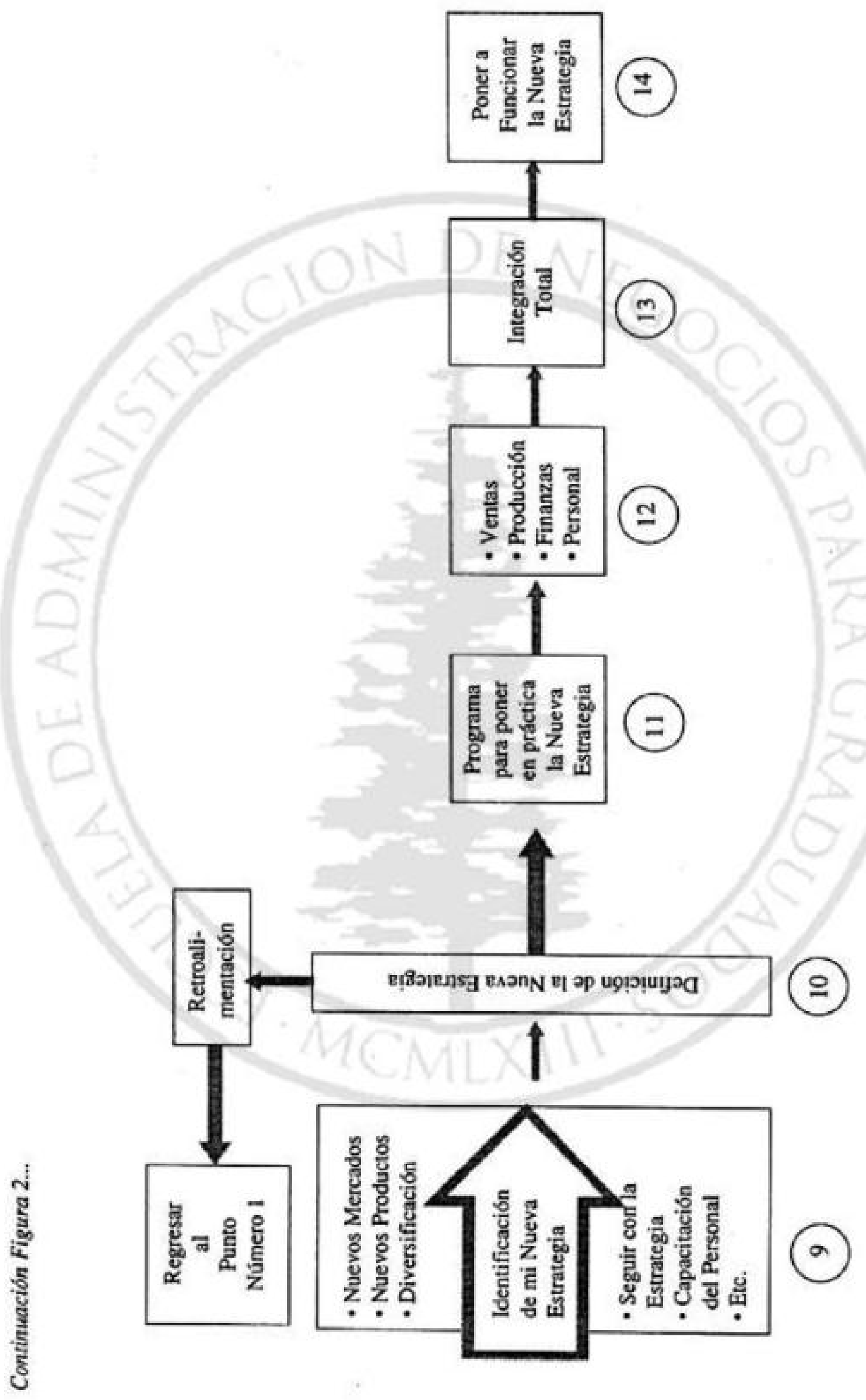




\section{Cuadro 1}

MEXTEX, S.A.: FSTADO DE RESULTADOS

del $1^{*}$ de enero al 31 de dieiembre de 1988

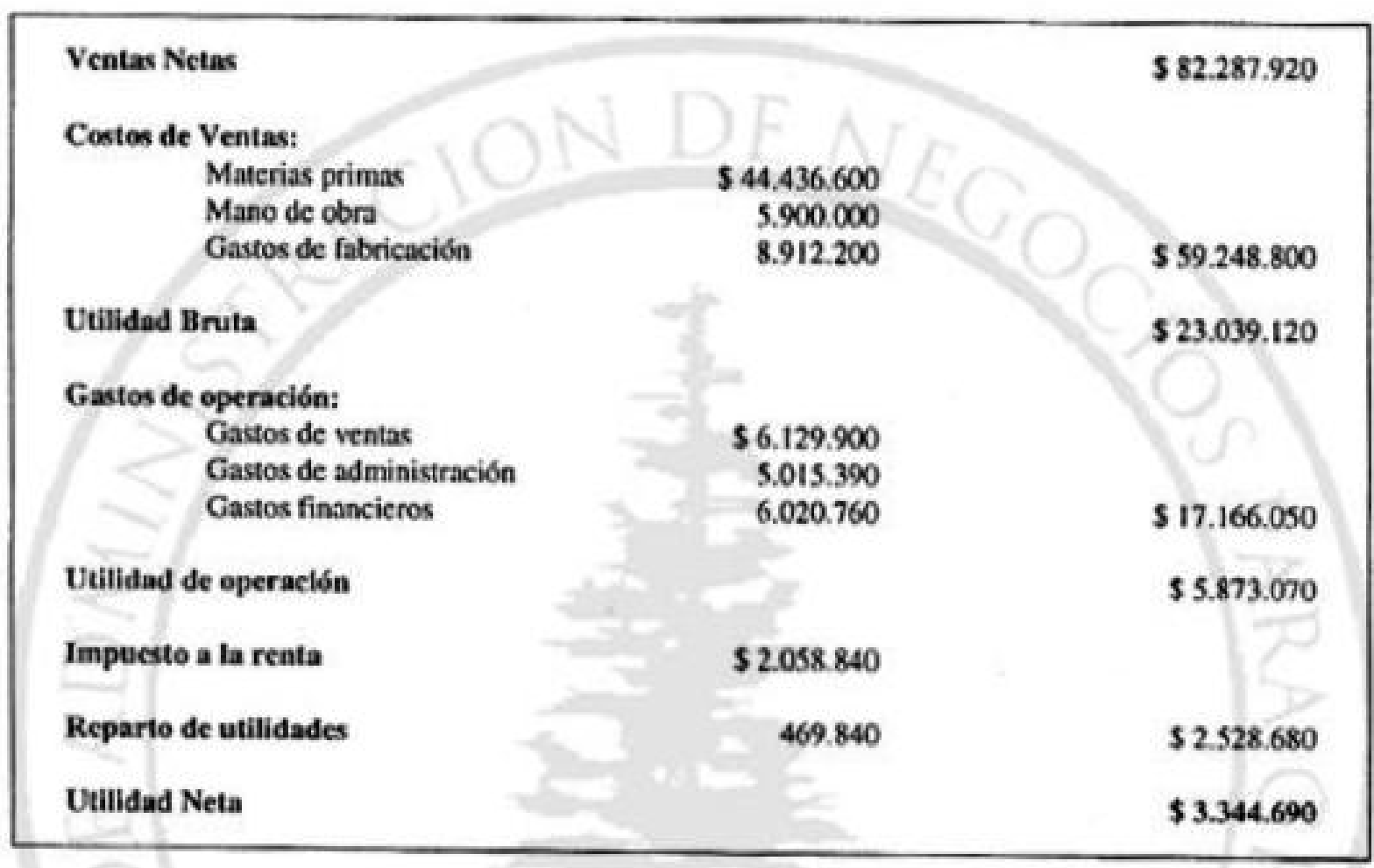


Cuadro 2

MEXTEX, S.A.: BALANCE GENERAL

al 31 de diciembre de 1988

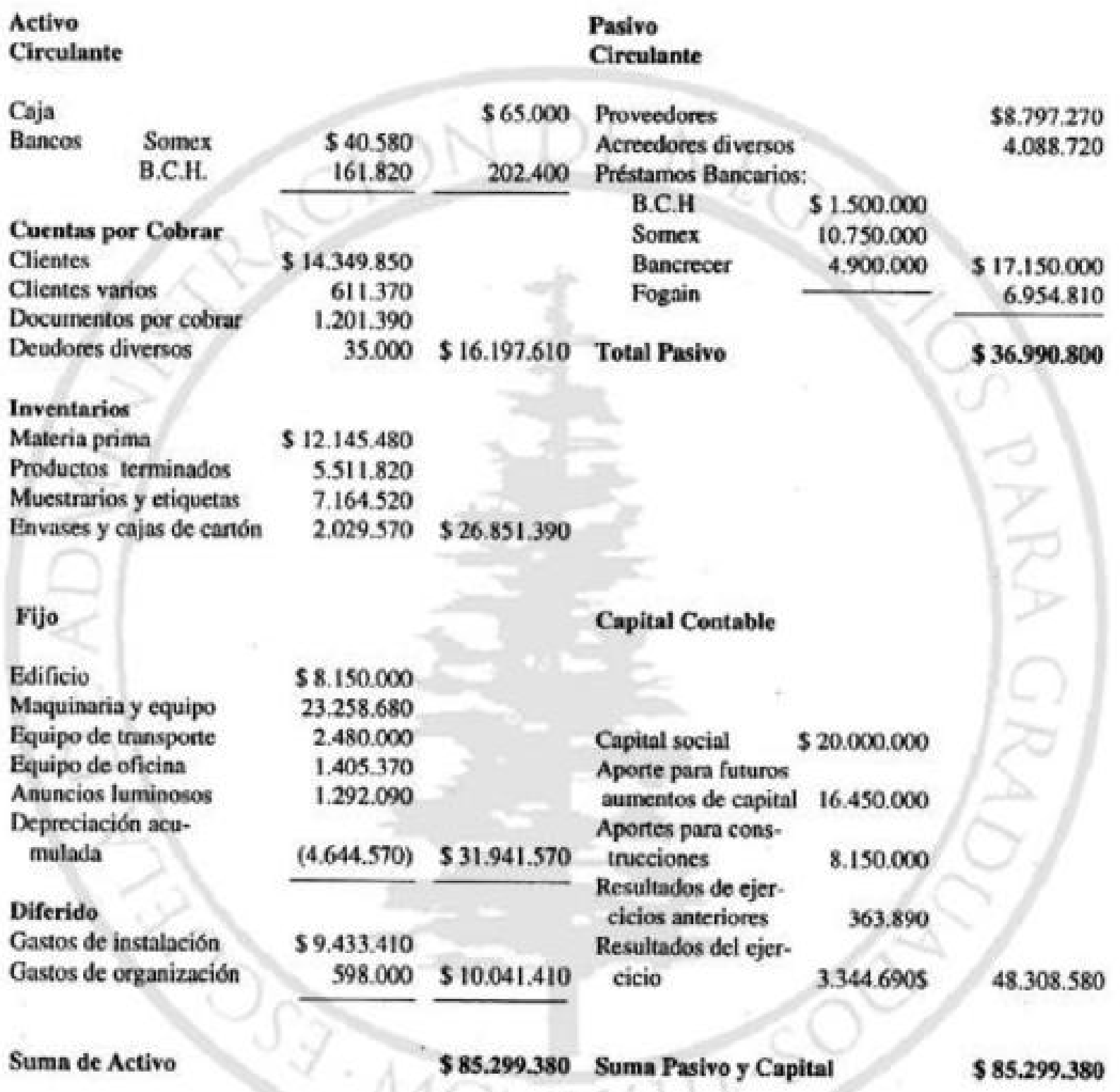




\section{Cuadro 3}

MEXTEX, S.A.: ESTADO DE RESULTADOS

del $1^{\circ}$ de enero al 30 de junio de 1989

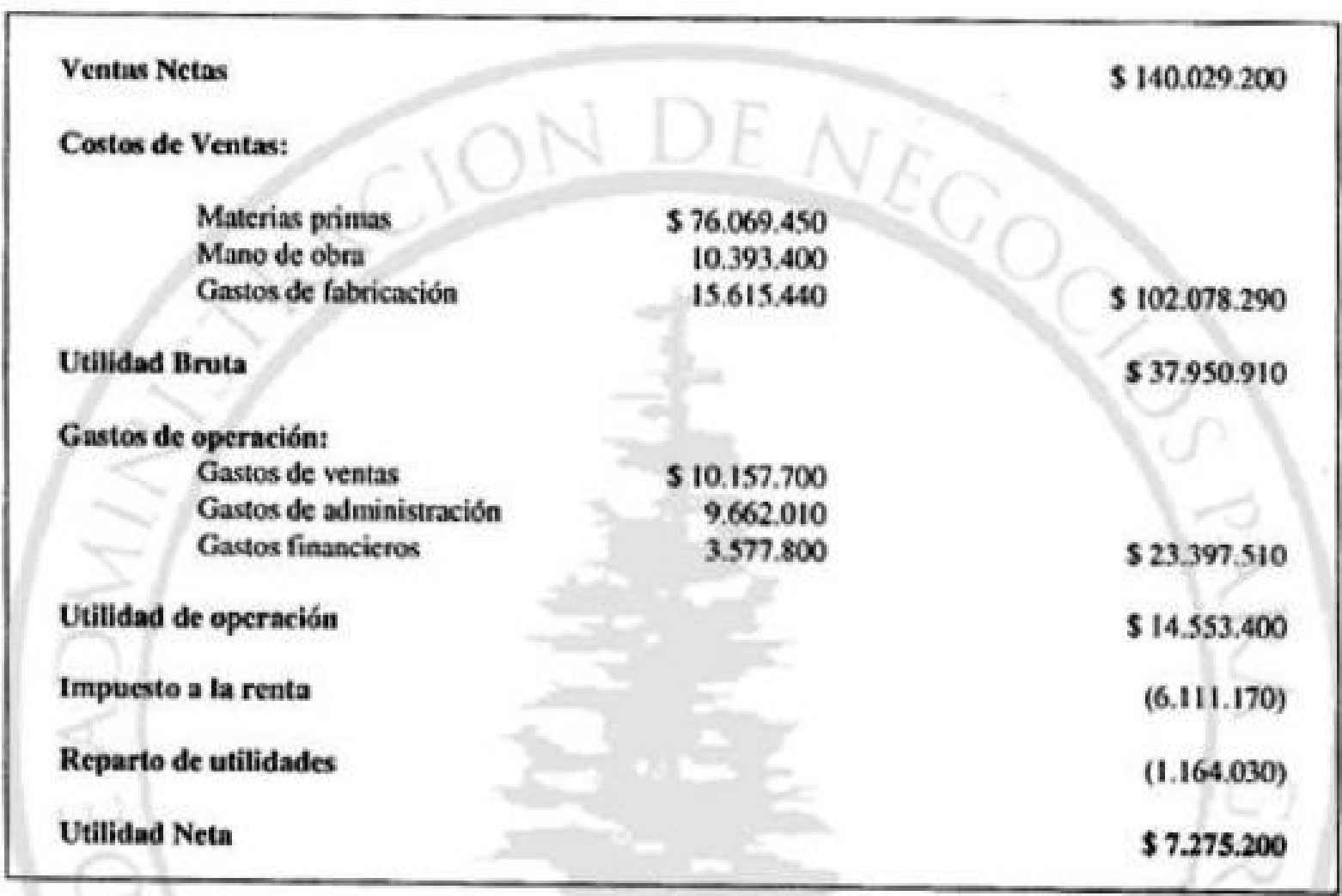




\section{Cuadro 4 \\ MEXTEX, S.A.: BALANCE GENERAL \\ al 30 de junio de 1989}

Activo

Circulante

Caja y bancos

Clientes

Documentos por cobrar

Deudores diversos

Inventarios:

Materia Prima

Productos terminados

Muestrarios y etiquetas

Envases y cajns de cartón

Fijo

Edificio

Maquinaria y equipo

Equipo de transporte

Equipo de ofieina

Anuncios luminosos

Depreciación

acumulada

Revaluación de activos fijos

Total Activo Fijo

Diferido

Pagos anticipados

Gastos instalación

Gastos de organización

-Amortizacion acumu. Lada

Total Activo Diferido

Suma de Activo
Pasivo

Circulante

Proveedores

$\$ 15.515 .380$

Docurnentos por pagar

11.334 .720

Acreedores diversos

Préstamos bancarios

4.900 .000

1. 200.930

$\$ 30.033 .060$

14.151 .650

1.720 .010

3.319 .800

977.880

$\$ 20.169 .340$

so

8.328 .910

40.079 .010

Fijo

Prestamos

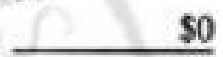

Suma Pasivo Total

$\$ 40.079 .010$

\$ 8.150 .000

23.419 .640

2.480 .000

1.405 .370

1.292 .090

$\frac{(6.382 .030)}{\$ 129.022 .900}$

Capital Contable

Capital Social

Aportes para futuros aumentos de capital

Resultados de ejercicios anteriores

Resultados del ejercicio

Superávit por

Revaluación

$\$ 20.000 .000$

24.600 .000

3.707 .580

7.275 .200

129.022 .900

$\$ 184.605 .680$

$\$ 14.734 .320$

Total Capital Contable

$\mathbf{5 2 2 4 . 6 8 4 . 6 9 0}$ 